Vol. 2, n. 3 - Edição Especial: Ciclos Formativos em Ensino de Ciências.

\title{
Ensinar é Aprender: Desafios e Experiências no Estágio de Docência
}

\section{Teaching is Learning: Challenges and Experiences in Teaching Internship}

\author{
Rafaela Engers Günzel (rafaela.gunzel@gmail.com) \\ Programa de Pós-Graduação em Educação em Ciências - PPGEC \\ Universidade Federal do Rio Grande - FURG
}

Resumo: Este trabalho é um relato de experiência de uma estagiária, contando sobre os desafios de lecionar Física para uma turma do $9^{\circ}$ ano do Ensino Fundamental. A experiência contada, foi oportunizada durante o Estágio Curricular Supervisionado 3: Ciências no Ensino Fundamental, disciplina obrigatória do curso de Química Licenciatura da Universidade Federal da Fronteira Sul - Campus Cerro Largo, que habilita os egressos também ao ensino de Ciências. No relato, a estagiária descreve o desafio de encontrar caminhos para introduzir os conceitos de Física para a turma, apresentando na discussão, a análise de desenhos feitos pelos alunos durante a realização de uma atividade em que os alunos tiveram de desenhar a representação da Física partindo da seguinte questão norteadora "Como você vê a Física?" e explicar o desenho. A intencionalidade dessa atividade foi compreender as concepções dos alunos sobre a disciplina de Física, desmistificar a preconcepção dos alunos acerca dela, apresentando a eles posteriormente relações com o cotidiano.

Palavras-chave: Estágio Docente; Professor de Ciências; Formação Inicial.

Abstract: This paper is an internship experience report, telling about the challenges of teaching physics to a 9th grade class. The experience told was provided during Supervised Internship 3: Science in Elementary School, mandatory subject of the Chemistry graduation of the Universidade Federal da Fronteira Sul - Campus Cerro Largo, which also enables graduates to teach Science. In the report, the intern describes the challenge of finding ways to introduce the physics concepts to the class and, presents in the discussion, the analysis of drawings made by students during the performance of an activity in which students had to draw the representation of physics based on the following guiding question "How do you see physics?" and explain the drawing. The purpose of this activity was to understand the students 'conceptions about Physics as a subject, to demystify the students' preconceptions about it, presenting them, further, its relations with everyday life. 


\section{Vol. 2, n. 3 - Edição Especial: Ciclos Formativos em Ensino de Ciências.}

Keywords: Teaching Internship. Initial teacher education, Science teacher.

\section{CONTEXTUALIZAÇÃo}

O estágio docente supervisionado é uma etapa fundamental na constituição formativa do licenciando. É uma disciplina que fornece espaço e orientação para que o futuro professor adentre a sala de aula e experimente-a, construindo vivências formativas e experiências docentes. Pimenta e Lima (2006, p. 7) apontam que "o estágio tem de ser teórico-prático, ou seja, que a teoria é indissociável da prática”. Os autores apontam o estágio como atitude investigativa em que deve estar envolvida a reflexão e a intervenção na vida da escola, dos professores, dos alunos e da sociedade.

É por meio da constante reflexão e análise do saber teórico e prático que se dará a formação de um profissional crítico e reflexivo de sua prática. Assim, o educador como um importante mediador da aprendizagem, precisa refletir sobre os conteúdos que ensina e como ensina, a fim de intervir quando necessário na sua atividade docente. A reflexão da própria prática é necessária, considerando que o docente deve estar em constante atualização, para sentir-se preparado para enfrentar os desafios da heterogeneidade da sala de aula (Alarcão, 2005). Essa reflexão ainda é um desafio para muitos professores, mas nos possibilita perceber as dificuldades e limitações presentes nesta profissão, repensando o ensino por meio da nossa prática.

Neste relato apresento uma discussão reflexiva acerca do desafio que foi o Estágio Curricular Supervisionado 3: Ciências no Ensino Fundamental, disciplina obrigatória no curso de Química Licenciatura da Universidade Federal da Fronteira Sul (UFFS), Campus Cerro Largo. Na ocasião, o desafio foi introduzir os conceitos científicos de Física para o $9^{\circ}$ ano do Ensino Fundamental (EF). A Física, bem como a Química, costumam ser assustadoras aos alunos mesmo antes de iniciarem as aulas.

Na maioria das vezes, os alunos chegam imbuídos de curiosidade e motivação e “[...] em pouco tempo, o contato em sala de aula com esse novo componente curricular 


\section{Vol. 2, n. 3 - Edição Especial: Ciclos Formativos em Ensino de Ciências.}

torna-se uma vivência pouco prazerosa e, muitas vezes, chega a constituir-se numa experiência frustrante que o estudante carrega consigo por toda a vida" (BONADIMAN; NONENMBACHER, 2007, p. 196). O pavor de muitos alunos pelas disciplinas pode ter origem em diversos fatores, como a desvalorização do professor, a maledicência feita por outros alunos ou ainda o detrimento pela Física matemática em relação à teórica, que neste caso, os alunos pressupõem que terão dificuldades pelo fato de não gostarem de matemática. Assim, de antemão estão postas as dificuldades que vão vir a ter com essa disciplina e acreditam não gostar de Física e/ou Química.

Aqui adentro numa questão que precisei trabalhar durante todo o processo de planejamento de ensino: eu mesma não gostava de Física e da ideia de trabalhar ela em decorrência das próprias dificuldades de aprendizagem. Apesar disso, ao cursar a disciplina de Estágio, fui desafiada a introduzir a Física aos alunos do $9^{\circ}$ ano durante o estágio de docência. Portanto, já na fase dos planejamentos me indagava em como introduziria os conceitos de Física para a turma, de forma que conseguisse desmistificar a ideia inicial dos alunos acerca da disciplina, ao mesmo tempo em que me desafiava a romper meu próprio paradigma. Segundo expressam Bonadiman e Nonenmbacher (2007, p. 197) "muitas das dificuldades enfrentadas pelo professor de Física em sala de aula, principalmente as relacionadas com a questão do gostar e do aprender, a nosso ver podem ser contornadas por ele mesmo, com o auxílio de uma metodologia adequada de ensino".

Para tanto, como estagiária que quer se compreender como professora de Ciências, quis saber quais eram as concepções iniciais dos alunos sobre a Física, para introduzir o tema e ao mesmo tempo vencer meus próprios preconceitos sobre essa área de conhecimento. Como isso foi feito e em que contexto, está descrito no item a seguir, em que trago, ao descrever a atividade, um convite para saber o que os alunos apresentaram em suas concepções iniciais, o qual foi utilizado para discutir e introduzir os conceitos da tão "temida" Física. 


\section{Vol. 2, n. 3 - Edição Especial: Ciclos Formativos em Ensino de Ciências.}

\section{DESCRIÇÃO DAS ATIVIDADES}

O Estágio foi realizado na Escola Estadual de Educação Básica Eugênio Frantz no município de Cerro Largo. A turma de $9^{\circ}$ ano do Ensino Fundamental era composta por 22 alunos. Ainda durante o planejamento, pensando na importância de desenvolver a participação dos alunos na aula, decidi já na primeira aula, distribuir folhas e pedir para que cada um fizesse um desenho e o explicasse, tendo a seguinte questão norteadora escrita no quadro: “Como você vê a Física?". Depois pedi que cada um mostrasse seu desenho e se apresentasse, dizendo seu nome, idade e explicando seu desenho, conseguindo assim ter uma noção básica, ainda inicial, da sensação e concepção deles acerca da disciplina.

Dando continuidade a aula, busquei trazer exemplos de onde a Física se encontrava presente no nosso cotidiano, explicitando os porquês de estudar ela e sua importância, apresentando uma Física que não é só feita de cálculos e equações, buscando assim desmistificar a Física matemática, que assusta muitos alunos e trabalhando muito mais os aspectos da Física conceitual e cotidiana. Ao mesmo tempo, também, passando por um processo de reformulação da minha própria visão sobre a disciplina.

Os desenhos foram recolhidos (dos 20 alunos presentes na aula) para realizar um levantamento e análise posterior. Cada aluno explicou o significado de seu desenho, os quais possuem as mais diversas representações, sendo as mais recorrentes o lançamento de foguetes ligado ao espaço/universo e uma maçã relacionando a Newton e a gravidade, provavelmente eles já haviam visto algo sobre essas representações interligadas à física em outros espaços/tempos. São trazidos em destaque no item a seguir a fotografia de 6 desenhos dos 20 recolhidos, para discorrer sobre a questão problematizada. Cada aluno recebeu um número para preservar a sua identidade nos 


\title{
Vol. 2, n. 3 - Edição Especial: Ciclos Formativos em Ensino de Ciências.
}

desenhos, bem como, nas frases escritas explicando os desenhos que estão expostos ao decorrer da discussão.

\section{DISCUSSÃO DA PRÁTICA}

Destaco a importância de um professor ser pesquisador de sua própria prática, pois a partir de suas escritas tem a possibilidade de visualizar o que precisa mudar, o que é preciso ser feito em determinada turma, quais metodologias deram certo e em quais algumas mudanças precisam ser feitas.

o professor reflexivo é, pois, fundamentalmente, um professor investigador, pois ele e só ele é capaz de examinar sua prática, identificar seus problemas, formular hipóteses, questionar seus valores, observar o contexto institucional e cultural ao qual pertence participar do desenvolvimento curricular, assumir a responsabilidade por seu desenvolvimento profissional e fortalecer as ações em grupo. (MIRANDA 2006, p. 134).

Ao discutir a importância da reflexão na (re)construção do professor, apresentase uma escrita reflexiva que fiz sobre a primeira aula, a qual foi retirada do relatório de estágio:

\begin{abstract}
Não estava com grande entusiasmo para começar a trabalhar as aulas que havia planejado. Um aspecto positivo pra mim no planejamento e no desafio de trabalhar conceitos de física, com certeza foi ter começado a gostar da área ao compreender alguns conceitos, aquele famoso "AH!" de quem viu sentido nas coisas que nunca havia significado. Fico encantada quando vejo alguém tão feliz sendo professora, e também com os colegas que se demonstram prontos para atuar, entrar na sala de aula e dizer "vamos lá" e fazer andar a carroça. Eu não me senti super entusiasmada, muito menos preparada para entrar e achar que iria fazer uma mágica, sei que terei que evoluir muito e amadurecer muito ainda nesse processo de me tornar a professora e que não é mágico o ato de entrar na sala. Não saio dessa primeira aula frustrada, até porque não coloquei muito entusiasmo, mas saio com a sensação de que o primeiro dia do desafio intenso que é o estágio foi cumprido (Relatório de Estágio, 2017).
\end{abstract}

Nesse trecho é possível ver a sensação que tive ao cumprir o primeiro período enquanto docente, momento em que desenvolvi a atividade descrita neste relato. Com relação aos desenhos, propostos na atividade são muito interessantes. Alguns representaram, de maneira geral, pontos de interrogação e muitos números, apareceram 


\section{Vol. 2, n. 3 - Edição Especial: Ciclos Formativos em Ensino de Ciências.}

relógios, muitas equações, fantasmas, calculadoras, raios, carros, foguetes, maçãs, astronautas e alienígenas, o planeta Terra, futebol e luneta, essas foram às representações mais recorrentes.

Com relação às explicações feitas pelos alunos, o que mais apareceu foi velocidade e gravidade. Relações com o Universo e seus mistérios/descobertas também foi bastante explicitado. Ressalto o desenho de uma aluna que representou a Terra toda de preto e seu eixo de rotação, explicando que aquela era a visão dela da Terra em movimento vista de algum lugar do Espaço, explicação peculiar em que se percebe a vivacidade da imaginação dos alunos, e a atividade proposta oportunizou essa expressão.

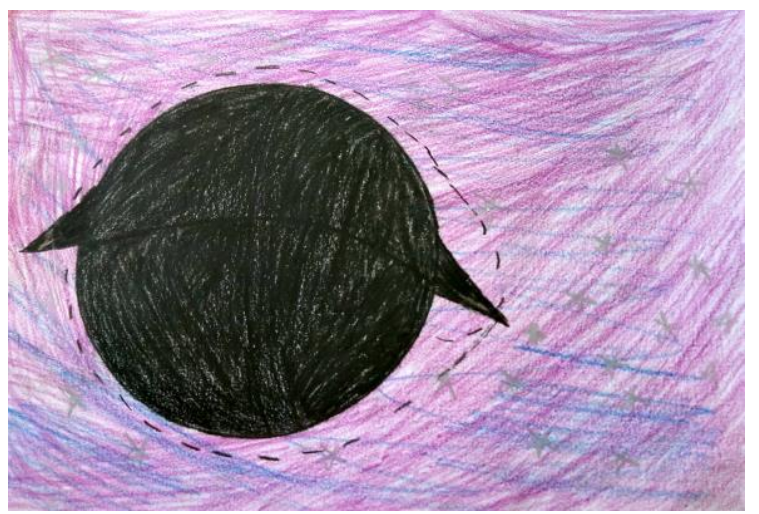

Figura 1 - O mundo em movimento (aluno 5).

Com essa questão retratada, percebo o quão interessante - além de importante, é possibilitar meios de expressão aos alunos, instigando que eles representem por alguma linguagem suas compreensões iniciais tornando possível desmistificar muitas coisas assustadoras, que por alguma razão desgostam. A imaginação não se trata de um dom, ou dado objetivo, ela é subjetiva e está ligada à inteligência e às emoções (GIRARDELLO, 2011), por isso, podemos considerar o desenho como a representação do pensamento, das concepções dos alunos.

A imaginação esteve em alta nos desenhos dos alunos representando a Física, além do desenho anterior, a seguir temos: a Física como um fantasma. O aluno 12 
Revista Insignare Scientia

\section{Vol. 2, n. 3 - Edição Especial: Ciclos Formativos em Ensino de Ciências.}

escreveu no desenho que: "O fantasma encontrou algo mais assustador que ele, no caso a física!".

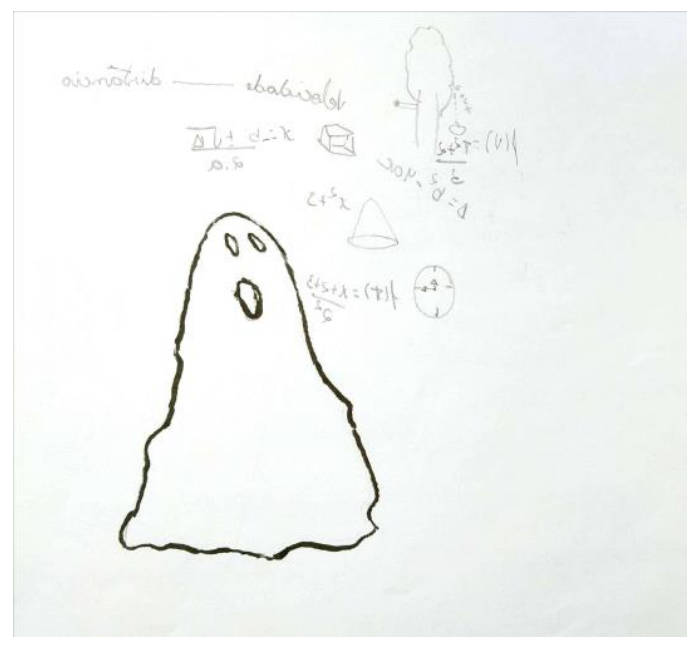

Figura 2 - O fantasma (aluno 12).

A perspectiva da Física como uma Ciência que estuda conhecimentos de cunho mais complexo, para além de nossa capacidade e uso cotidiano é recorrente nas concepções dos alunos. Por isso reafirmo a necessidade de permear as concepções dos alunos sobre essa área do conhecimento, explorando seus pensamentos sobre o tema em questão, para que como professores, possamos identificar as necessidades dos alunos para com a área em estudo.

É fundamental destacar que o cunho teórico-metodológico utilizado pelo professor é capaz de motivar o aluno propiciando condições para gostar de estudar e aprender, e que "essa importância fica evidenciada para o aluno se o professor atribuir significado à Física por ele ensinada na escola, satisfazendo, dessa forma, parte da curiosidade do estudante, que comumente é explicitada pela conhecida pergunta: para quê serve isso, professor?” (BONADIMAN; NONENMBACHER, 2007, p. 198).

Podemos pensar nessa pergunta olhando o desenho a seguir, onde o aluno representou o Universo (galáxia), com astronautas, foguetes, estrelas e extraterrestres, 


\section{Vol. 2, n. 3 - Edição Especial: Ciclos Formativos em Ensino de Ciências.}

sendo a vida fora da Terra algo que os cientistas ainda estão em busca e muitas vezes aparecem nos meios de comunicação.

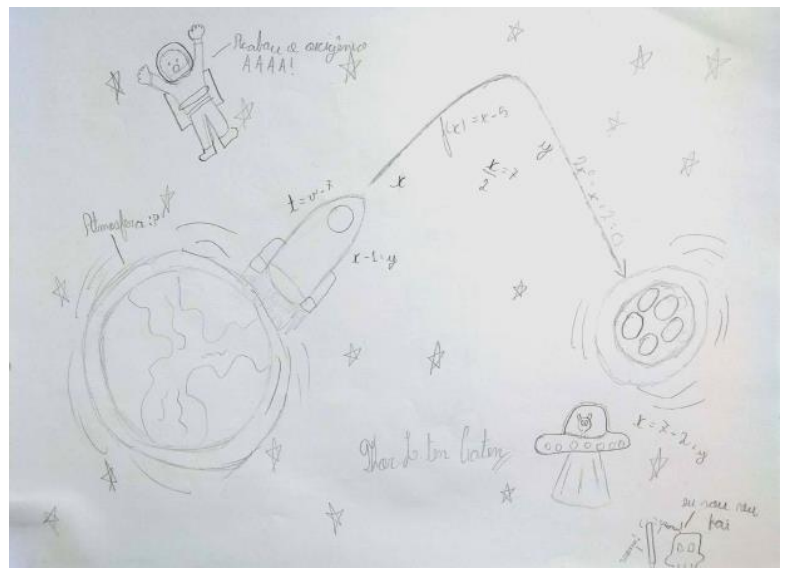

Figura 3 - Universo (aluno 3).

Reportando-me à pergunta "para que serve isso?", é possível expor, por exemplo: para que serve descobrir se há vida fora do planeta Terra? Podendo dar subsídio para uma ampla discussão em sala de aula, envolvendo os alunos e dando oportunidade para que ele se posicione frente ao assunto. Pois referente aos nossos alunos, "há um continuado desafio: o quanto nós educadores e educadoras de professoras e professores somos capazes de envolvê-los nas discussões dos problemas que lhes são mais próximos" (CHASSOT, 2011, p. 140).

Assim, abrimos as possibilidades para além da Física descontextualizada, pois geralmente dá-se privilegio para a teoria e abstração. "O ensino de Física tem-se realizado frequentemente mediante a apresentação de conceitos, leis e fórmulas, de forma desarticulada, distanciados do mundo vivido pelos alunos e professores e não só, mas também por isso, vazios de significado" (BONADIMAN; NONENMBACHER, 2007, p. 199), como representado no desenho do aluno 19 a seguir. 
Revista Insignare Scientia

Vol. 2, n. 3 - Edição Especial: Ciclos Formativos em Ensino de Ciências.

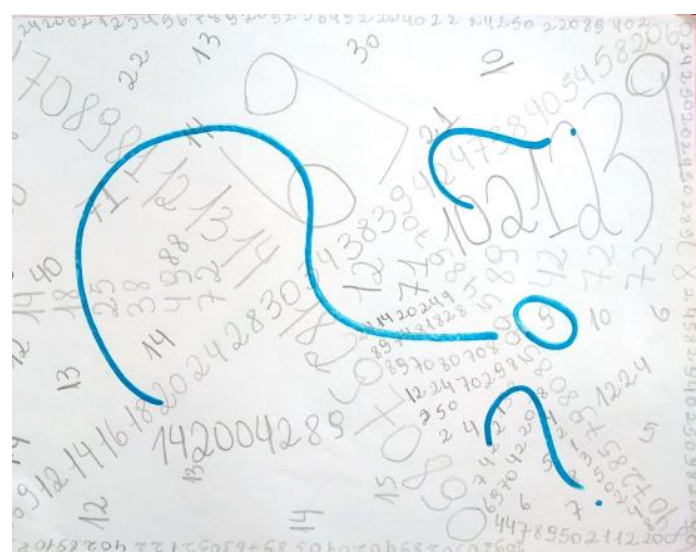

Figura 4 - Matemática (aluno 19).

Esse aluno expressou após o primeiro contato com a disciplina de Física que: "Bom, eu enxergava a física como uma coisa assustadora, pois nem sabia direito o que era. Agora descobri que a física são cálculos que envolvem tempo, velocidade, etc, e que estão no nosso dia a dia". Essa fala é uma exemplificação da importância do trabalho docente ao relacionar os conceitos científicos com o cotidiano, mostrando evidências de que o que estamos estudando, se faz de fato presente em nossas vidas e nas coisas que realizamos diariamente. Observando os dois desenhos a seguir:

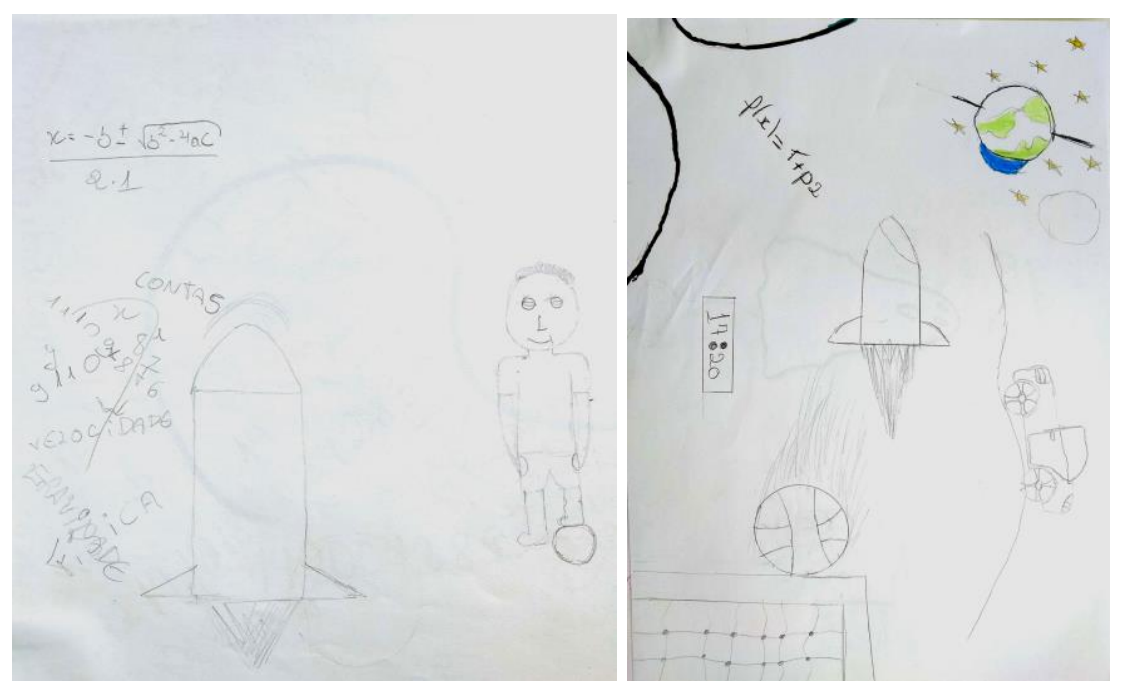

Figura 5 e 6 - Como vejo a Física (aluno 9 e aluno 15). 


\section{Vol. 2, n. 3 - Edição Especial: Ciclos Formativos em Ensino de Ciências.}

A relação com o cotidiano é possível de ser observada nos desenhos, onde os alunos, além das equações, desenharam representações de futebol e um carro, comtemplando atividades que realizam no dia a dia: prática de esportes e locomoção. Um dos alunos descreveu em seu desenho que a "Física envolve tudo o que está ao nosso redor" (aluno 9).

Encerrando este tópico de discussão, afirmo que o ato de "[...] ensinar ciências é procurar que nossos alunos e alunas se transformem, com o ensino que fazemos, em homens e mulheres mais críticos" (CHASSOT, 2011, p. 56), pois quando adentramos na sala de aula, enquanto professores, sabemos muito pouco sobre os alunos, não sabemos quem são ou o que esperam da escola, como aprendem e como podem vir a ter prazer na aprendizagem que vamos dialogar neste espaço (DELIZOICOV; ANGOTTI e PERNAMBUCO, 2002). Assim, precisamos conhecer mais nossos alunos e tentar compreender um pouco do que pensam.

\section{CONCLUSÃO}

O Estágio Docente foi muito além de me constituir professora. Ele possibilitou que eu desafiasse meus medos e desmistificasse meus próprios paradigmas, especialmente sobre a Física, área que eu sentia dificuldade em aprender. O processo de ensino e aprendizagem no contexto escolar potencializa a formação dos sujeitos aprendentes, que incluem os professores. Aprendi muito mais sobre Física ao ter que lecionar os conceitos científicos, do que propriamente sendo aluna. Com a vivência do estágio, em todo seu contexto, que envolve planejamento desde muito antes de adentrar a sala de aula, concluo que aprendi muito mais do que ensinei.

Espero que esse relato tenha conseguido transparecer que não precisamos saber todos os conceitos científicos, pois com ato de lecionar teremos sempre muito para aprender. Esse estágio em especial, aconteceu em um período conturbado da política do Estado, onde os professores com seus salários parcelados aderiram à greve do magistério. Na ocasião conclui a carga horária do estágio docente com outras atividades 
Revista Insignare Scientia

\section{Vol. 2, n. 3 - Edição Especial: Ciclos Formativos em Ensino de Ciências.}

pedagógicas. Reafirmo que esse fato não prejudicou de forma alguma minha constituição como professora, pois vim de um longo processo de Iniciação à Docência por meio do projeto PETCiências, do Programa de Educação Tutorial (PET), o que reforça em âmbito nacional a extrema importância e necessidade da continuidade de programas com esse objetivo, o qual inclui-se o PIBID (Programa Institucional de Bolsas de Iniciação à Docência) e o Residência Pedagógica.

\section{REFERÊNCIAS}

ALARCÃO, I. Professores reflexivos em uma escola reflexiva. Cortez, 2005.

BONADIMAN, H.; NONENMBACHER, S. E. B. O GOSTAR E O APRENDER NO ENSINO DE FISSICA: UMA PROPOSTA METODOLÓGICA. Caderno Brasileiro do Ensino de Física, v. 24, n. 2: p. 194-223, 2007.

CHASSOT, Attico. Alfabetização Científica: questões e desafios para a educação. Ijuí: Unijuí: 2011.

DELIZOICOV, Demétrio; ANGOTTI, José André; PERNAMBUCO, Marta Maria. Ensino de Ciências: Fundamentos e Métodos. São Paulo: Cortez, 2003.

GIRARDELLO, G. Imaginação: arte e ciência na infância. Pro-Posições, v. 22, n. 2, p. 75-92, 2011.

MIRANDA, M. G. de. O Professor Pesquisador e Sua Pretensão de Resolver a Relação Entre a Teoria e a Prática na Formação de Professores. In: O Papel da pesquisa na formação e na prática dos professores. Campinas: Papirus, 2006.

PIMENTA, Selma Garrido; LIMA, Maria Socorro Lucena. Estágio e docência: diferentes concepções. Revista Poíesis, v.3, n. 3 e 4, p. 5-24, 2006. 